\title{
Kinetic study of the pyrolysis and combustion of tomato plant
}

\author{
R. Font, J. Moltó, A. Gálvez * M.D. Rey \\ Department of Chemical Engineering, University of Alicante, P.O. Box 99, E-03080 Alicante, Spain
}

\section{A R T I C L E I N F O}

Article history:

Received 30 June 2008

Accepted 21 November 2008

Available online $\mathrm{xxx}$

Keywords:

Pyrolysis

Combustion

Tomato plant

Kinetics

\begin{abstract}
A B S T R A C T
A kinetic study of the thermal decomposition of tomato plant has been carried out under different conditions by TG and TG-MS. A total of 24 experiments were performed in a nitrogen atmosphere (pyrolysis runs) and also in an oxidative atmosphere with two different oxygen concentrations ( $10 \%$ and $20 \%$ oxygen in nitrogen). Dynamic runs and dynamic + isothermal runs have been carried out to obtain many data of decomposition under different operating conditions.

A scheme of five independent reactions for pseudocomponents has been proposed for the pyrolysis process, although only three fractions have probed to be significant, comparing the weight fractions of volatiles evolved with the hemicellulose, cellulose and lignin content of the plant. For the combustion runs, four new reactions have been added: two competitive oxidation reactions for the cellulose and lignin, and two combustion reactions of the carbonaceous residue obtained from pyrolysis. The kinetic parametres have been calculated by integration of the differential equations and minimizing the differences between the experimental and calculated values. It is important to emphasize that the same set of parameters has been proposed for the pyrolysis and combustion runs, and which do not depend on either the heating rate in dynamic runs or whether the run is carried out in a dynamic or isothermal mode. The influence of the oxygen pressure has been also discussed.
\end{abstract}

(c) 2008 Elsevier B.V. All rights reserved.

\section{Introduction}

Tomato plant is an agricultural waste that is normally decomposed and burnt on the field. Burning can be a problem due to the generation of pollutants that can be introduced in the feeding chain through the new plants, so logically recollection of these wastes and the exploitation of their energetic potential can be interesting.

Gonzalez et al. [1,2] studied the combustion of three types of pellets, one of them from tomato residue in boilers for domestic use. Mangut et al. [3] carried out a thermogravimetric study of the thermal decomposition of residues from the tomato processing industry: peels, seeds and peels + seeds. They considered 13 fractions, obtaining for each one of them the corresponding kinetic parameters of the thermal decomposition. Müller-Hagedorn and Bockhorn [4] studied the behaviour of two types of maize plants in low temperature pyrolysis, considering the kinetic parameters of the maize plant and those obtained from the hemicellulose, cellulose and lignin. No references have been found in literature concerning the pyrolysis and combustion of tomato plants and the

\footnotetext{
* Corresponding author. Tel.: +34 96590 3546; fax: +34 965903826 .

E-mail address: ara.galvez@ua.es (A. Gálvez).
}

references to other plants are scarce, so the contribution of this paper can be important.

\section{Experimental}

\subsection{Raw material}

The sample employed in this study was tomato plant obtained from the Alicante area (Spain). The material was milled to an average size of $1 \mathrm{~mm}$. Table 1 presents the elemental and moisture analysis of the material studied. The elemental analysis of the main components was carried out in a PerkinElmer 2400 and the ash residue was obtained by calcination at $850{ }^{\circ} \mathrm{C}$. The moisture content was determined by the weight loss at $105^{\circ} \mathrm{C}$ for $12 \mathrm{~h}$. Chlorine was measured (semiquantitative determination) using an automatic sequential spectrometer X-ray Fluorescence model TW 1480. Solubilized-ethanol, hemicellulose, cellulose and lignin contents were also determined for this materials [5-8]. The samples used for the TG runs were dried and kept under $4^{\circ} \mathrm{C}$ in a freezer. Previously to the runs, the samples were in contact with atmospheric air, so they may have taken some humidity from the environment, making the value different. 
Table 1

Characteristics of the material used.

\begin{tabular}{lc}
\hline Moisture (wt.\%) & 16.6 \\
Composition on dry basis & \\
C (wt.\%) & 38.3 \\
H (wt.\%) & 5.2 \\
N (wt.\%) & 2.7 \\
S (wt.\%) & 1.1 \\
Ash content (wt.\%) & 11.6 \\
O \% by difference (wt.\%) & 41.1 \\
Cl (wt.\%) & 8.96 \\
Ethanol extract (wt.\%) & 5.1 \\
Hemicellulose (wt.\%) & 28.8 \\
Cellulose (wt.\%) & 39.1 \\
Lignin (wt.\%) & 12.1 \\
\hline
\end{tabular}

\subsection{Thermobalance}

A Mettler Toledo thermobalance model TGA/SDTA851e/LF/ 1600 with TG-DTA was used to carry out the TG experiments. This apparatus has a horizontal furnace and a parallel-guided balance. The position of the sample has no influence in the measurement, and flow gas perturbation and thermal buoyancy are minimized. The sample temperature was measured with a sensor placed just under the sample holder.

For the pyrolysis runs, the atmosphere used was $\mathrm{N}_{2}$. Two atmospheres were used in the presence of oxygen: $\mathrm{N}_{2}: \mathrm{O}_{2} 4: 1(20 \%$ $\mathrm{O}_{2}$ ) and $\mathrm{N}_{2}: \mathrm{O}_{2}$ 9:1 $\left(10 \% \mathrm{O}_{2}\right)$. The flow rate was $100 \mathrm{ml} \mathrm{min}^{-1}$.

Dynamic experiments were carried out at different heating rates between 5 and $60 \mathrm{~K} \mathrm{~min}^{-1}$, from ambient temperature to a final temperature higher than $1000 \mathrm{~K}$, covering in this way an extensive range of decomposition. Dynamic + isothermal experiments started with a constant heating rate until the set temperature was obtained, and then the final temperature was maintained constant throughout the pyrolysis or combustion process for a long period of time. The final temperatures for the isothermal + dynamic runs were selected inside an extensive interval of temperatures, considering those where the decomposition rates in dynamic runs were high. The weight of sample used was around $5 \mathrm{mg}$, and under these conditions, it was tested with many different materials with strongly endo or exothermic decomposition processes that the heat transfer effect was very small.

An experiment with a heating rate of $5 \mathrm{~K} \mathrm{~min}^{-1}$ using Avicel PH105 microcrystalline cellulose was carried out additionally. The kinetic values obtained showed good agreement with the results presented by Grønli et al. [9] in their round-robin study of cellulose pyrolysis kinetics by thermogravimetry. This experiment was used to check the good performance of the thermobalance.

The TG/MS runs were carried out in the same thermobalance previously indicated coupled to a Thermostar GSD301T Pfeiffer Vacuum MS apparatus with the following operating conditions: weight sample around $10 \mathrm{mg}$, heating rate $30 \mathrm{~K} \mathrm{~min}^{-1}$, ionization $70 \mathrm{eV}$, SIR (selected ion recording) detection of several ions $(\mathrm{m} / \mathrm{z}$ ): $4,13-18,25-32,35-46$ and the following ions in another run: 4, $32,43-46,50-52,55-58,60,65,68,73,78,91,96,105,106$. In the TG/MS experiments, the gases employed were $\mathrm{He}$ and $\mathrm{He}: \mathrm{O}_{2}(4: 1)$ It was tested that the very small oxygen concentration in the helium used can cause a small oxidation of the sample and/or the volatiles evolved. The response of the different ions was divided by that of helium $(m / z=4)$ and substracted from that corresponding to the beginning of the run.

\section{Results and discussion}

\subsection{Experimental results}

Fig. 1 shows the TG plots for tomato plant pyrolysis (nitrogen) at heating rates of $5,10,20$ and $60 \mathrm{~K} \mathrm{~min}^{-1}$. In the Figure, the
Tomato plant. $\mathbf{N}_{2}$

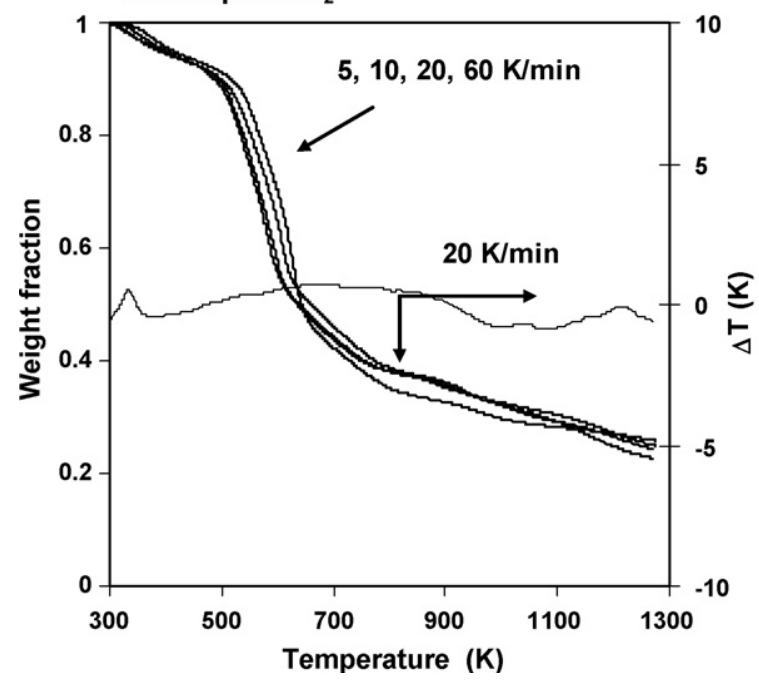

Fig. 1. Tomato plant pyrolysis at 5, 10,20 and $60 \mathrm{~K} \mathrm{~min}^{-1}$. Experimental curves (the calculated curves overlap the experimental ones).

weight fraction represents the residual weight fraction of the solid, sum of the residue formed and the non-reacted initial solid. For a run, the DTA results are also plotted on the right $Y$-axis in a logical scale, from $-10 \mathrm{~K}$ for a strongly endothermic process to $+10 \mathrm{~K}$ corresponding to a strongly exothermic process. It can be observed that there are small variations of temperature. The high percentage of inorganic material in the sample can make the variation due to the vaporization of the humidity be small.

Fig. 2 shows the TG and DTG curves for a run which provide more information about the fractions that can be taken into account in the decomposition. It can be observed that there is an initial small peak, a wide band as a result of the overlapping of at least three fractions and finally another small peak.

Fig. 3 shows the intensities of some ions in a TG/MS run in He, corresponding to $\mathrm{H}_{2} \mathrm{O}(\mathrm{m} / \mathrm{z} 18), \mathrm{CO}_{2}(\mathrm{~m} / \mathrm{z} 44), \mathrm{CO}(\mathrm{m} / \mathrm{z} 28)$ and $\mathrm{CH}_{4}$ $\left(\mathrm{m} / \mathrm{z} 15\right.$, corresponding to $\mathrm{CH}_{3}+$; the evolution of the ions $12,13,15$ and 16 are similar). The variation of the weight loss can also be observed. For the water, there is an initial peak, due to the

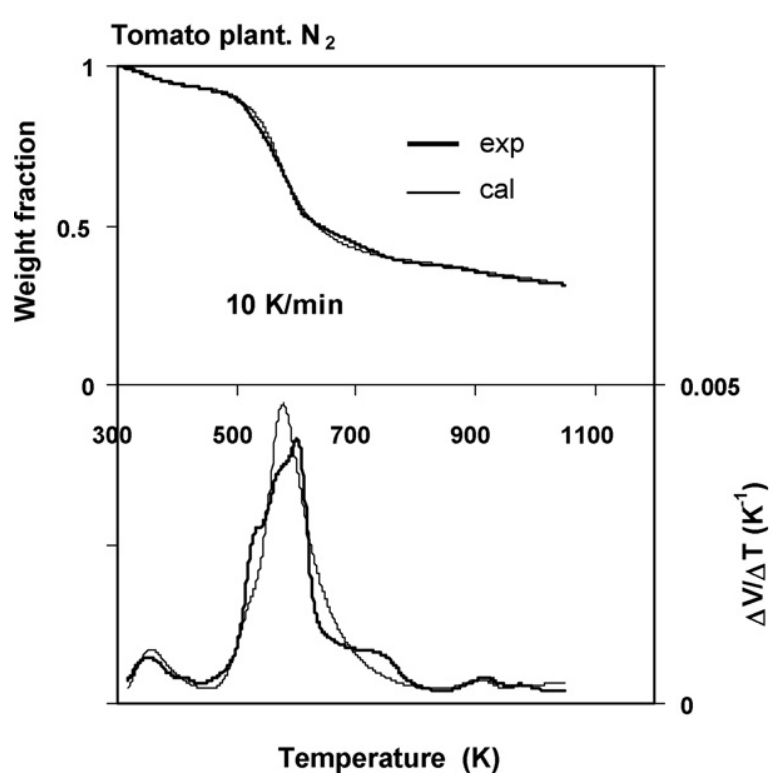

Fig. 2. Weight fraction and its derivative from a pyrolysis run. 
Tomato plant. He

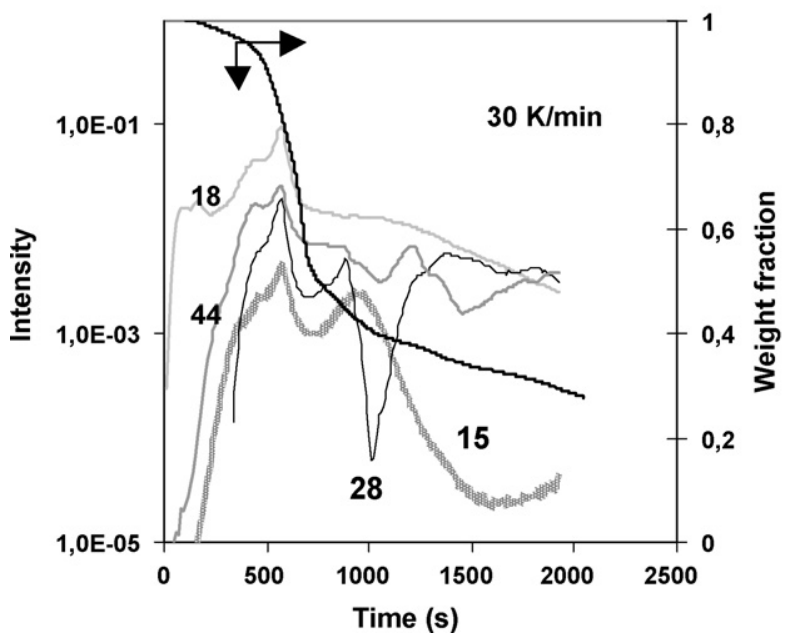

Fig. 3. Variation of ions $(m / z) 15\left(\mathrm{CH}_{4}\right), 18\left(\mathrm{H}_{2} \mathrm{O}\right), 28(\mathrm{CO})$ and $44\left(\mathrm{CO}_{2}\right)$ in a pyrolysis TG-MS run (He atmosphere).

humidity of the sample, and then the overlapping of different fractions in a wide band is observed.

Five dynamic + isothermal experiments were carried out for the pyrolysis of the sample. These experiments started with a heating rate until the desired temperature was reached, and then the final temperature was maintained constant throughout the pyrolysis process. Fig. 4 shows the experimental values for these five runs.

Fig. 5 shows the experimental TG plots of combustion runs $\left(\mathrm{N}_{2}: \mathrm{O}_{2} 4: 1\right)$ at three heating rates $\left(5,10,20 \mathrm{~K} \mathrm{~min}^{-1}\right)$. The $\Delta T$ corresponding to the DTA analysis is also plotted and an initial small endothermic peak (evaporation of the humidity) is observed, afterwards, a small exothermic peak appears due to oxidative pyrolysis, and later, there is a significant exothermic process in the last part of the decomposition due to the combustion of char or carbonaceous residue.

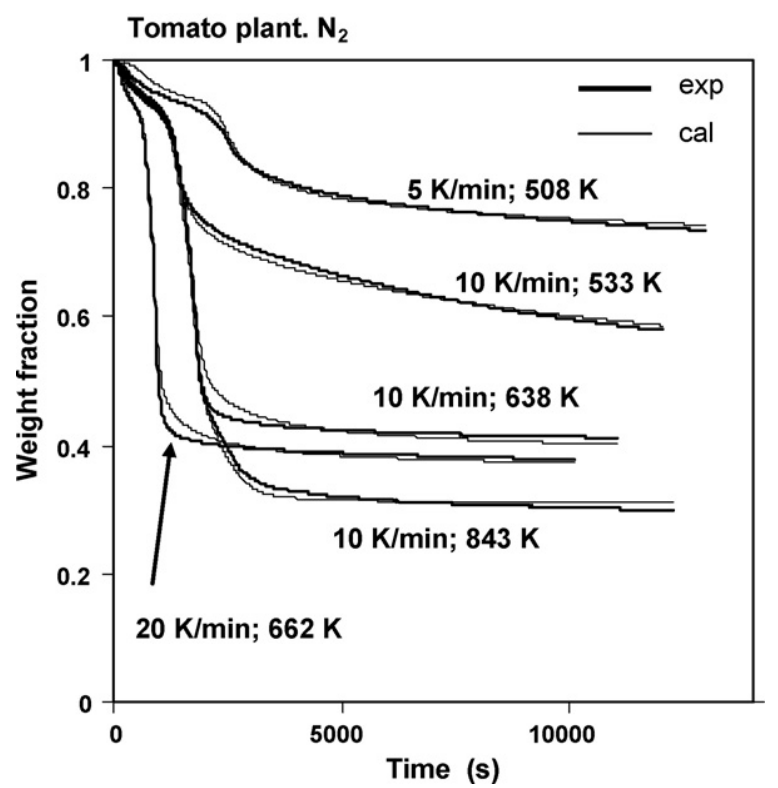

Fig. 4. Dynamic + isothermal runs in $\mathrm{N}_{2}$ atmosphere. Experimental and calculated curves.
Tomato plant. $\mathrm{N}_{2}: \mathrm{O}_{2} 4: 1$

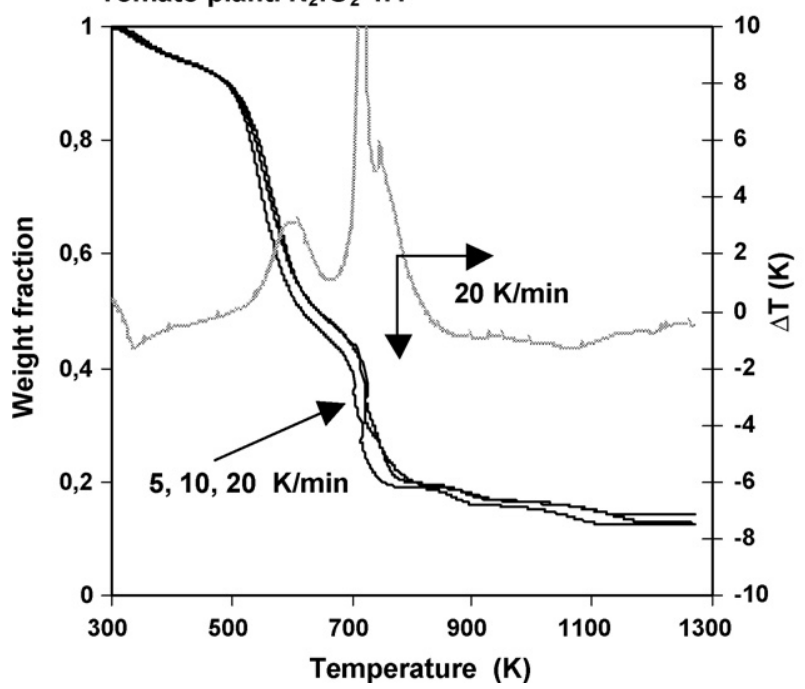

Fig. 5. Tomato plant combustion at 5,10 and $20 \mathrm{~K} \mathrm{~min}^{-1}$. Experimental curves (the calculated curves overlap the experimental ones).

Fig. 6 shows the weight fraction and its derivative for a dynamic run of combustion, indicating that there is an initial small evolution of volatiles (humidity), three subsequent fractions and two final small fractions at the last part.

The variation of the ion intensities of a combustion dynamic TG/ MS run (in $\mathrm{He}: \mathrm{O}_{2} 4: 1$ ) is plotted vs. time in Fig. 7, indicating the overlapping of at least three fractions in the central part of the decomposition process. Fig. 8 shows the experimental results of six dynamic + isothermal runs, obtained with different operating conditions $\left(\mathrm{N}_{2}: \mathrm{O}_{2} 4: 1\right)$. Whereas, Figs. 9 and 10 show the experimental results of the dynamic and dynamic + isothermal runs in a 9:1 $\mathrm{N}_{2}: \mathrm{O}_{2}$ atmosphere.

According to the results of the TG, DTG and TG/MS analysis, in order to obtain good correlation models, five fractions in the pyrolysis runs (humidity and three fractions probably corresponding to hemicellulose, cellulose and lignin together with a final small fraction) must be considered. Regarding the combustion runs, another small fraction that decomposes at high temperature has also been taken into account.

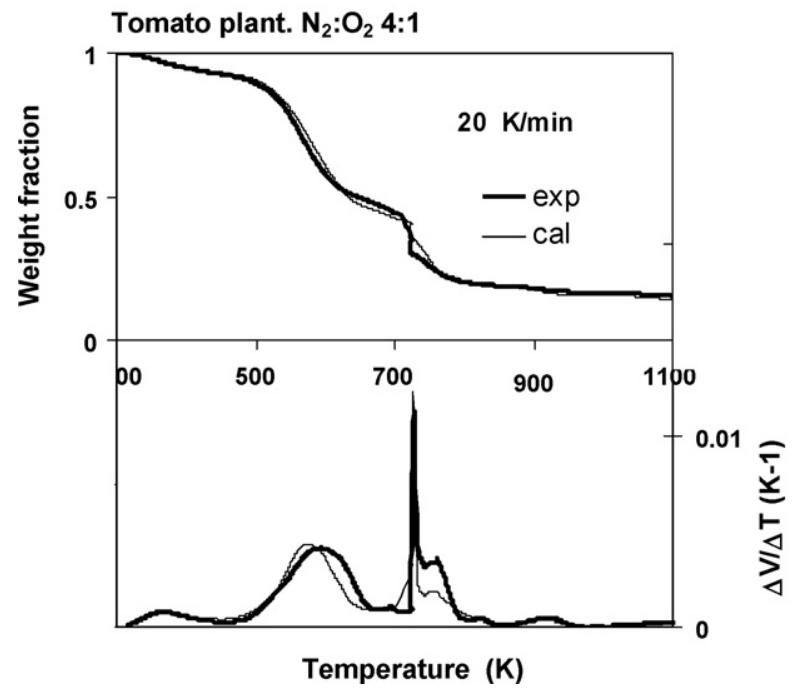

Fig. 6. Weight fraction and its derivative from a combustion run. 
Tomato plant. He:02 4:1

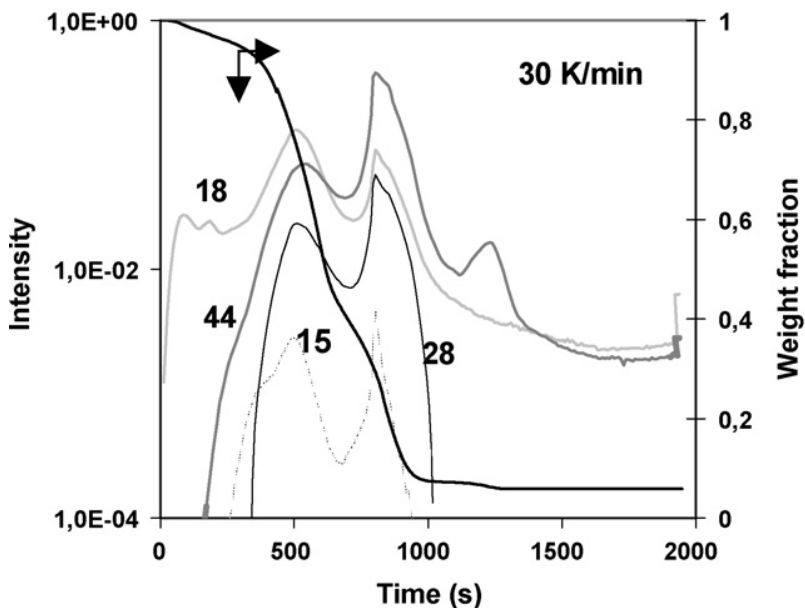

Fig. 7. Variation of ions $15\left(\mathrm{CH}_{4}\right), 18\left(\mathrm{H}_{2} \mathrm{O}\right), 28(\mathrm{CO})$ and $44\left(\mathrm{CO}_{2}\right)$ in a combustion TG-MS run ( $\mathrm{He}: \mathrm{O}_{2}$ atmosphere).

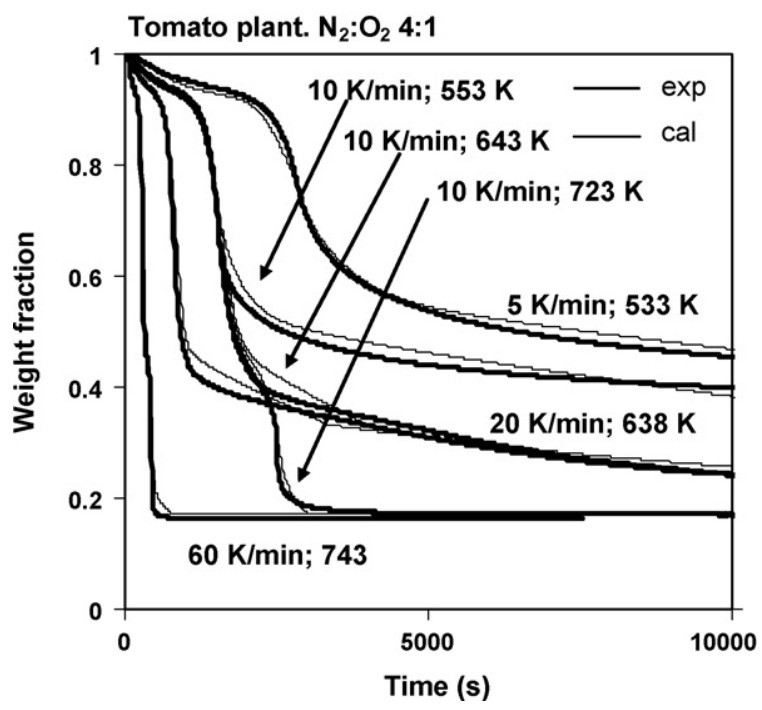

Fig. 8. Dynamic + isothermal runs in N2:O2 4:1 atmosphere. Experimental and calculated curves.

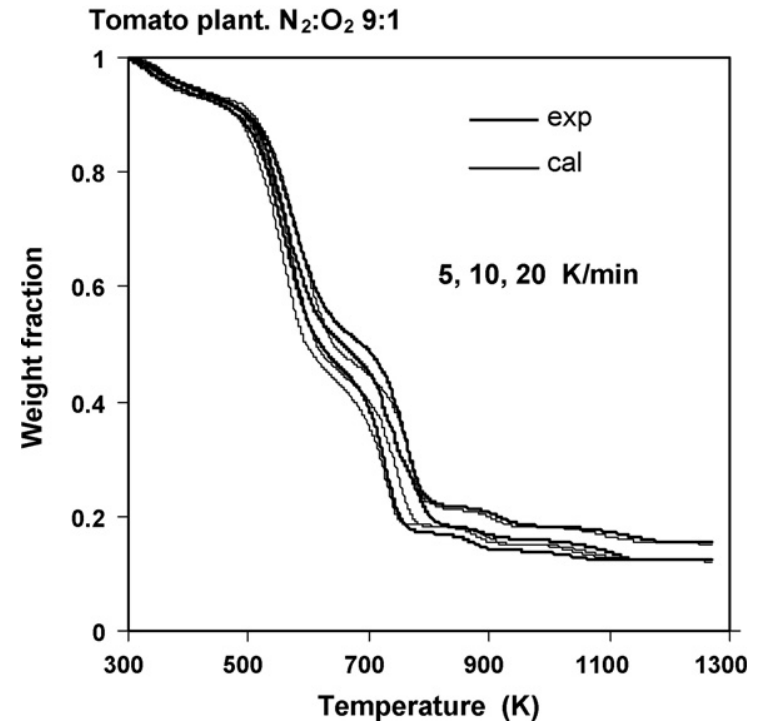

Fig. 9. Tomato plant oxidative pyrolysis (N2:02 9:1) at 5, 10 and $20 \mathrm{~K} \mathrm{~min}^{-1}$. Experimental curves (the calculated curves overlap the experimental ones).

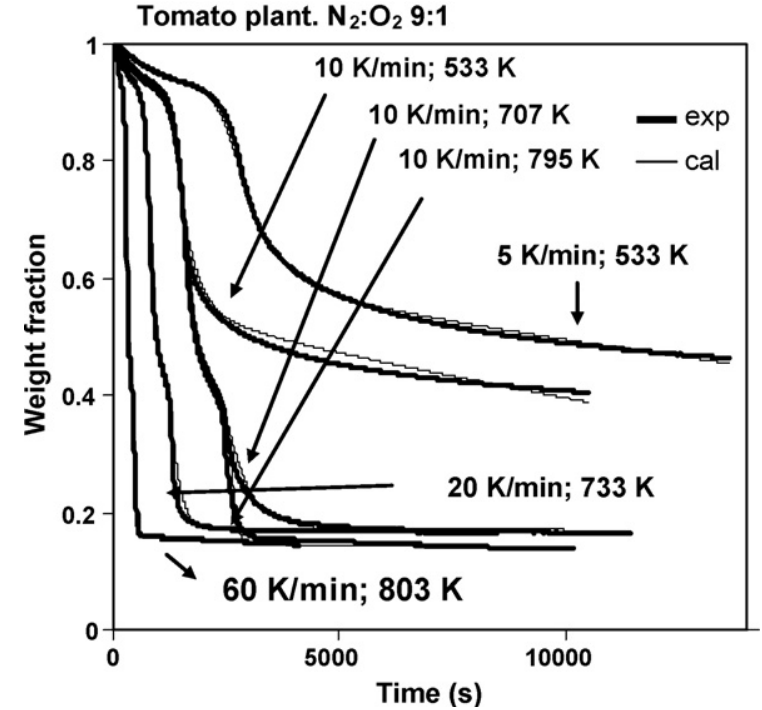

Fig. 10. Dynamic + isothermal runs in a N2:O2 9:1 atmosphere. Experimental and calculated runs.

\subsection{Pyrolysis model}

Five fractions have been considered in the kinetic model proposed in pyrolysis:

wolid $_{1} \stackrel{1}{\longrightarrow} v_{1 \infty}$ Volatiles $_{1}$

Wolid $_{2} \stackrel{2}{\longrightarrow} v_{2 \infty}$ Volatiles $_{2}$

$w_{\text {Solid }_{3}} \stackrel{3}{\longrightarrow}\left(w_{s_{30}}-v_{3 \infty}\right)$ Char $_{3}+v_{3 \infty}$ Volatiles $_{3}$

$w_{\text {Solid }_{4}} \stackrel{4}{\longrightarrow}\left(w_{s_{40}}-v_{4 \infty}\right)$ Char $_{4}+v_{4 \infty}$ Volatiles $_{4}$

$w_{\text {Solid }_{5}} \stackrel{5}{\longrightarrow}\left(w_{s_{50}}-v_{5 \infty}\right)$ Char $_{5}+v_{5 \infty}$ Volatiles $_{5}$

In the previous scheme and for reactions 1 and 2, it has been considered that there is no formation of residues because these reactions are associated with the humidity and volatiles (fraction 1 ) and with hemicellulose and other volatiles (fraction 2). In this scheme, this consideration does not affect the evolution of volatiles, but for the combustion scheme, the consideration of formation of char or carbonaceous residue that finally is burnt does not improve the correlation of the data.

In the previous reactions, 'Solid 1 ', 'Solid 2 ', . .'Solid 5 ' refer to the different fractions of the raw material, 'Volatiles' $i$ are the gases + volatiles evolved in the corresponding reactions $(i=1-5)$, and 'Char' ${ }_{i}$ is the char or carbonaceous residue formed in the decomposition of each $\operatorname{Solid}_{i}(i=3-5)$. On the other hand, the small letters represent the yield coefficients representative of each reaction and consequently. The yield coefficient represents the maximum weight fractions obtainable by each reaction. In this way, $\mathrm{v}_{i \infty}$ is the yield coefficient for the Volatiles $_{i}$, which coincides with the maximum weight fraction of volatiles at infinite time that can be evolved.

The conversion degree for each reaction is defined as the ratio between the weight fraction of solid reacted at any time $\left(w_{i 0}-w_{i}\right)$ and the corresponding initial fraction of this component $w_{i 0}$, or the ratio between the weight fraction of volatiles obtained at any time 
$\left(V_{i}\right)$ and the corresponding yield coefficient or the:

$\alpha_{i}=\frac{w-w}{w}=\frac{V_{i}}{v_{i \infty}} \quad i=1$ to 5

where $w_{i 0}$ is the weight fraction of each Solid ${ }_{i}$ that is in the original material, and consequently

$\sum_{i=0}^{5} w=1$

From the weight balance between products and reactants and the conversion degrees, the kinetic equations for the pyrolysis runs can be expressed as follow:

$$
\begin{aligned}
-\frac{d\left(\frac{w}{w}\right)}{d t} & =\frac{d\left(\frac{V_{i}}{v_{i \infty}}\right)}{d t}=\frac{d \alpha_{i}}{d t}=k_{i}\left(\frac{w_{i}}{w}\right)^{n_{i}}=k_{i}\left(1-\alpha_{i}\right)^{n_{i}} \\
& =k_{i}\left[1-\frac{V_{i}}{v_{i \infty}}\right]^{n_{i}}
\end{aligned}
$$

with the kinetic constants following the Arrhenius equation:

$k_{i}=k_{i 0} \exp \left(-\frac{E_{i}}{\mathrm{RT}}\right) \quad i=1$ to 5

By integration of these equations, it is possible to calculate $\alpha_{1}$ to $\alpha_{5}$ at each time if the temperature program is known. The relationship between $\alpha_{i}$ values and the weight fraction measured in the thermobalance $(w)$ is related with the volatiles obtained $(V)$ by

$$
\begin{aligned}
w & =1-V \\
& =1-F_{V}\left(v_{1 \infty} \alpha_{1}+v_{2 \infty} \alpha_{2}+v_{3 \infty} \alpha_{3}+v_{4 \infty} \alpha_{4}+v_{5 \infty} \alpha_{5}\right)
\end{aligned}
$$

Note that in the correlation of the TG data only the weight of volatiles evolved can be obtained and the residue content is the difference between the unity and the sum of the weight fractions corresponding to the volatiles evolved at infinite time. In addition, a correcting factor $F_{v}$ has been introduced in Eq. (5), due to the fact that the samples introduced can have a light but significantly different content of inert material (dust, humus, etc.). In all the cases the $F_{V}$ values are between 0.95 and 1.05. Although an effort was done to obtain homogeneous sample, small differences in the ash contents were obtained. Note that the mixing of an inorganic material with the organic fraction of the tomato plants may not be perfect.

\subsection{Combustion model}

The combustion model proposed to explain the thermal decomposition of the material is shown in the following scheme:

Pyrolysis reactions:

wolid $_{1} \stackrel{1}{\longrightarrow} v_{1 \infty}$ Volatiles $_{1}$

$w_{\text {Solid }_{2}} \stackrel{2}{\longrightarrow} v_{2 \infty}$ Volatiles $_{2}$

$w$ Solid $_{3} \stackrel{3}{\longrightarrow}\left(w-v_{3 \infty}\right)$ Char $_{3}+v_{3 \infty}$ Volatiles $_{3}$

$w_{\text {Solid }_{4}} \stackrel{4}{\longrightarrow}\left(w-v_{4 \infty}\right)$ Char $_{4}+v_{4 \infty}$ Volatiles $_{4}$

Combustion of char 3 and char 4 :

$$
\begin{aligned}
& \left(w-v_{3 \infty}\right) \text { Char }_{3}+\mathrm{O}_{2} \stackrel{3 c}{\longrightarrow} v_{3 c \infty} \text { Volatiles }_{3 c}+\left(w-v_{3 \infty}\right. \\
& \left.\quad-v_{3 c \infty}\right) \text { Ash }_{3 c} \\
& \left(w-v_{4 \infty}\right) \text { Char }_{4}+\mathrm{O}_{2} \stackrel{4 c}{\longrightarrow} v_{4 c \infty} \text { Volatiles }_{4 c}+\left(w-v_{4 \infty}\right. \\
& \left.\quad-v_{4 c \infty}\right) \text { Ash }_{4 c}
\end{aligned}
$$

Competitive oxidative pyrolysis reactions for $\mathrm{Solid}_{3}$ and $\mathrm{Solid}_{4}$ without formation of char:

$$
\begin{aligned}
& \text { wSolid }_{3}+\mathrm{O}_{2} \stackrel{3 c p}{\longrightarrow} v_{3 c p \infty} \text { Volatiles }_{3 c p}+\left(w-v_{3 c p \infty}\right) \text { Ash }_{3 c p} \\
& \text { wSolid }_{4}+\mathrm{O}_{2} \stackrel{4 c p}{\longrightarrow} v_{4 c p \infty} \text { Volatiles }_{4 c p}+\left(w-v_{4 c p \infty}\right) \text { Ash }_{4 c p}
\end{aligned}
$$

Reaction of two minor fractions:

$w_{\text {Solid }_{5}} \stackrel{5}{\longrightarrow}\left(w-v_{5 \infty}\right)$ Ash $_{5}+v_{5 \infty}$ Volatiles $_{5}$

wSolid $_{6} \stackrel{6}{\longrightarrow}\left(w-v_{6 \infty}\right)$ Ash $_{6}+v_{6 \infty}$ Volatiles $_{6}$

This scheme has been proposed after analysing the results with other schemes with different number of reactions, and considering the shape of the curves presented previously. In this model, it has been considered after the previous results of correlations, that the reaction rate is proportional to the oxygen pressure because the optimized value of reaction order with respect to the oxygen was close to 1 in the combustion reactions. For the competitive reactions $3 \mathrm{cp}$ and $4 \mathrm{cp}$, initially a dependence of the preexponential factor with the oxygen pressure was considered, obtaining a reaction order for the oxygen pressure around zero. Consequently, it has been considered that these reactions do not depend on the oxygen pressure.

The kinetic equations, considering conversions degree are the following:

$\frac{d \alpha_{i}}{d t}=k_{i}\left(1-\alpha_{i}\right)^{n_{i}} \quad$ for $\quad i=1,2$ and 5,6

$\frac{d \alpha_{i}}{d t}=k_{i}\left(1-\alpha_{i}-\alpha_{i c p}\right)^{n_{i}} \quad$ for $\quad i=3,4$

$\frac{d \alpha_{i c p}}{d t}=k_{i c p}\left(1-\alpha_{i}-\alpha_{i c p}\right)^{n_{i c p}} \quad$ for $\quad$ ic $p=3 \mathrm{cp}, 4 \mathrm{cp}$

Note that the reactions $\mathrm{R} 3$ and $3 \mathrm{cp}$ and $\mathrm{R} 4$ and $4 \mathrm{cp}$ are competitive. On the other hand, there are also two consecutive reactions as a consequence of the oxidation of the char or carbonaceous residue, so

$\frac{d \alpha_{i c}}{d t}=k_{i c}\left(\alpha_{i}-\alpha_{i c}\right)^{n_{i c}} \quad$ for $\quad$ ic $=3 \mathrm{c}, 4 \mathrm{c}$

where the pre-exponential factor $k_{i c}$ is directly proportional to the oxygen pressure, and can be written as

$k_{i c}=k_{i c}^{*}\left(\frac{p_{\mathrm{O}_{2}}}{0.20}\right) \quad\left(p_{\mathrm{O}_{2}}\right.$ in atm $)$

where $p_{\mathrm{O}_{2}}$ is the partial pressure of oxygen in atm, and logically $k_{\text {ic }}$ equals $k_{i c}$ when working with $\mathrm{N}_{2}: \mathrm{O}_{2} 4: 1$ atmosphere $\left(p_{\mathrm{O}_{2}}\right.$ equals $0.20 \mathrm{~atm})$.

The total weight fraction and the volatile weight fraction $V$ are related to the conversion degrees by

$$
\begin{gathered}
w=1-V=1-F_{v}\left(v_{1 \infty} \alpha_{1}+v_{2 \infty} \alpha_{2}+v_{3 \infty} \alpha_{3}+v_{4 \infty} \alpha_{4}+v_{5 \infty} \alpha_{5}\right. \\
\left.+v_{6 \infty} \alpha_{6}+v_{3 c p \infty} \alpha_{3 c p}+v_{4 c p \infty} \alpha_{4 c p}+v_{3 c \infty} \alpha_{3 c}+v_{4 c \infty} \alpha_{4 c}\right)
\end{gathered}
$$

where $\boldsymbol{v}_{i \infty}, \boldsymbol{v}_{i c p \infty}, \boldsymbol{v}_{i c \infty}$ and represent the maximum value of volatiles in the corresponding reaction without possible competence with other reactions, and coincide with the corresponding yield coefficients. The correction factor $F_{v}$ has been also included, with values between 0.95 and 1.05 . 


\subsection{Kinetic parameters}

The dynamic runs and the dynamic + isothermal runs for both pyrolysis and combustion were correlated with the same set of parameters. The calculated values were obtained by integration of the differential equations presented in the kinetic model by the Euler method considering and testing that the intervals of time were small enough to make errors be negligible. The optimization method of the Solver function in a spreadsheet Excel was used to minimize the differences between experimental and calculated weight loss values. The objective function (OF) to minimize was the sum of the square differences between experimental and calculated weight loss values and in some cases the derivatives were also included with a weight factor.

$\mathrm{OF}=\sum_{m=1}^{M} \sum_{i=1}^{N}\left(V_{m i}^{\exp }-V_{m i}^{c a l}\right)^{2}+$ factor $\sum_{m=1}^{M} \sum_{i=1}^{N}\left(\frac{d V_{m, i}^{\exp }}{d t}-\frac{d V_{m, i}^{c a l}}{d t}\right)^{2}$

$M$ : number of points, $N$ : number of runs

The model validity was tested calculating the variation coefficient (VC):

$\mathrm{VC}=\frac{\sqrt{\left(\sum_{m=1}^{M} \sum_{i=1}^{N}\left(V_{m i}^{\mathrm{exp}}-V_{m i}^{c a l}\right)^{2}\right) /\left(N_{\text {total }}-P\right)}}{\overline{V_{\mathrm{exp}}}} \times 100$

where $N$ and $P$ are the number of data and parameters fitted, respectively, and the denominator is the average of the experimental weight fraction of volatiles evolved.

The optimization was carried out in terms of a 'comparable kinetic constant' $K_{i}^{*}$ instead of optimizing $k_{0 i}$. This constant $K_{i}^{*}$ was calculated at a temperature around the maximum decomposition rate $\left(T_{\max }\right)$. Value 0.64 was obtained from the optimization program for decreasing the great interrelation between the pre-exponential factor, the apparent activation energy and the reaction order [10].

$K_{i}^{*}=k_{i}(0.64)^{n_{i}}=k_{o i} \exp \left(\frac{-E_{i}}{\left(R T_{\max }\right)}\right)(0.64)^{n_{i}}$

It must be emphasized that all the data, pyrolysis, oxidative pyrolysis and combustion, dynamic runs with different heating rates and distinct dynamic + isothermal runs, were correlated at the same time. On the other hand, the inclusion of isothermal runs causes difficulties in obtaining acceptable correlations, compared to the case when only dynamic runs are considered.

Table 2 shows the set of parameters optimized. The variation coefficient is a small value around $4 \%$, considering that many runs have been simultaneously correlated with the same set of parameters. Figs. 11 and 12 show the variation of weight fraction of volatiles vs. temperature. It was obtained that the volatiles fraction in the reactions 4 and $4 \mathrm{c}$ were very small (Fig. 12), so they have been neglected and the corresponding kinetic parameters have not been presented in Table 2 to avoid misinterpretations. The calculated curve variations are also plotted in some figures shown previously, overlapping the experimental results in many cases. It can be concluded that the correlations are quite good.

For solid fraction 3, there are two competitive reactions, one leading to a char or carbonaceous residue that is later oxidized by reaction $3 c$, and other second competitive reaction $3 \mathrm{cp}$. The maximum value of volatile fractions of reactions 3 and $3 c$, in accordance with Table 2 , equals 0.429 , which coincides with the volatile weight fraction of reaction $3 \mathrm{cp}$. In Fig. 12, the variation of volatile weight fraction is plotted, and the sum of the weight fractions of the reactions $3+3 \mathrm{c}$ and $3 \mathrm{cp}$ at the end of the run equals 0.429 , due to the fact that they are competitive, but logically the weight fractions of $3+3 c$ and $3 \mathrm{cp}$ at infinite time must be lower than the maximum possible if each one was alone. The volatile
Table 2

Kinetic parameters obtained for the pyrolysis and combustion.

\begin{tabular}{lllrl}
\hline Reaction & Mass fraction V & $k\left(\mathrm{~s}^{-1}\right)$ & $E(\mathrm{~kJ} / \mathrm{mol})$ & $n$ \\
\hline Pyrolysis & & & & \\
1 & 0.085 & $1.251 \times 10^{8}$ & 67.4 & 4.68 \\
2 & 0.152 & $1.302 \times 10^{10}$ & 122.2 & 3.36 \\
3 & 0.410 & $1.442 \times 10^{20}$ & 240.8 & 6.74 \\
4 & 0.095 & $1.211 \times 10^{1}$ & 79.4 & 1.48 \\
5 & 0.010 & $6.581 \times 10^{15}$ & 307.6 & 1.00 \\
Residue & 0.248 & & & \\
Combustion & & & & \\
1 & 0.085 & $1.251 \times 10^{8}$ & 67.4 & 4.68 \\
2 & 0.152 & $1.302 \times 10$ & 122.2 & 3.36 \\
3 & 0.184 & $2.630 \times 10^{20}$ & 240.8 & 6.74 \\
4 & & It is not important & & \\
5 & 0.030 & $6.581 \times 10^{15}$ & 307.6 & 1.00 \\
6 & 0.030 & $6.427 \times 10^{12}$ & 307.6 & 2.00 \\
$3 c$ & 0.245 & $1.274 \times 10^{11}$ & 184.7 & 0.87 \\
$4 \mathrm{c}$ & & It is not important & & \\
$3 \mathrm{cp}$ & 0.429 & $6.718 \times 10^{-2}$ & 36.1 & 0.00 \\
$4 \mathrm{cp}$ & 0.160 & $8.224 \times 10^{4}$ & 80.3 & 0.79 \\
Ash & 0.114 & & & \\
VC (\%) & 4.0 & & & \\
\hline
\end{tabular}

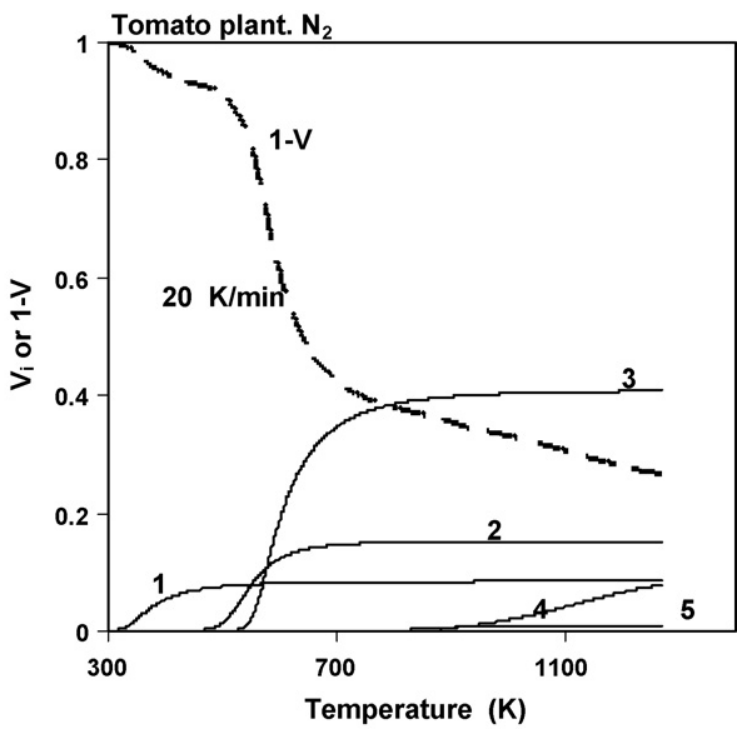

Fig. 11. Evolution of the mass fraction of volatiles for each reaction in a pyrolysis run.

Tomato plant. $\mathrm{N}_{2}: \mathrm{O}_{2} 4: 1$

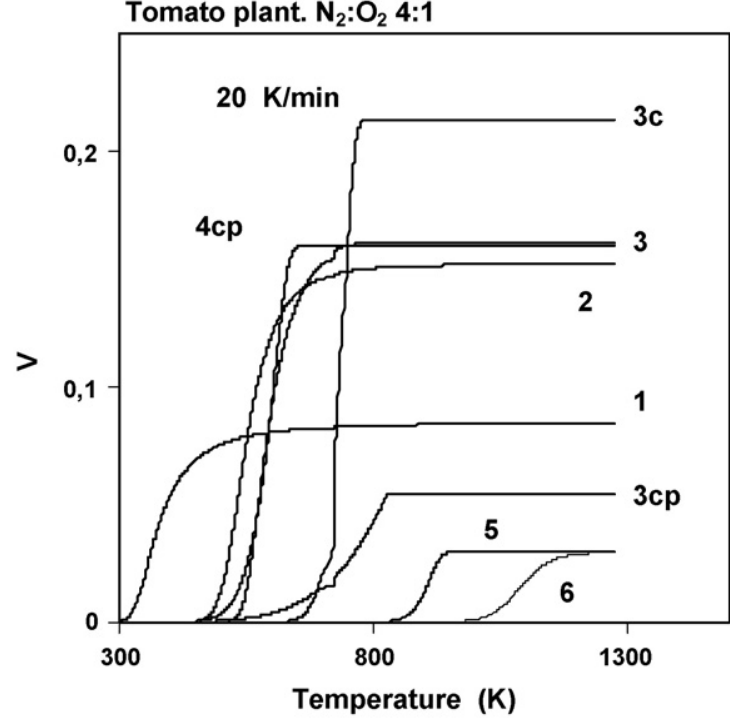

Fig. 12. Evolution of the mass fraction of volatiles for each reaction in a combustion run 
Table 3

Kinetic parameters for the pyrolysis and combustion considering first-order reactions.

\begin{tabular}{lllrl}
\hline Reaction & Mass fraction V & $k\left(\mathrm{~s}^{-1}\right)$ & $E(\mathrm{~kJ} / \mathrm{mol})$ & \multicolumn{1}{l}{$n$} \\
\hline Pyrolysis & & & & \\
1 & 0.070 & $2.168 \times 10^{7}$ & 63.6 & 1.00 \\
2 & 0.200 & $4.959 \times 10^{9}$ & 117.3 & 1.00 \\
3 & 0.313 & $9.087 \times 10^{17}$ & 144.3 & 1.00 \\
4 & 0.134 & $9.908 \times 10^{1}$ & 65.8 & 1.00 \\
5 & 0.010 & $6.581 \times 10^{15}$ & 307.6 & 1.00 \\
Residue & 0.273 & & & \\
Combustion & & & & \\
1 & 0.070 & $2.168 \times 10^{7}$ & 63.6 & 1.00 \\
2 & 0.200 & $4.959 \times 10^{9}$ & 117.3 & 1.00 \\
3 & 0.154 & $5.233 \times 10^{18}$ & 144.3 & 1.00 \\
4 & & It is not important & & \\
5 & 0.030 & $6.581 \times 10^{15}$ & 307.6 & 1.00 \\
6 & 0.030 & $6.427 \times 10^{12}$ & 307.6 & 1.00 \\
$3 \mathrm{c}$ & 0.267 & $1.880 \times 10^{11}$ & 160.6 & 1.00 \\
$4 \mathrm{c}$ & & It is not important & & \\
$3 \mathrm{cp}$ & 0.422 & $6.857 \times 10^{-2}$ & 56.6 & 1.00 \\
$4 \mathrm{cp}$ & 0.134 & $3.853 \times 10^{4}$ & 117.3 & 1.00 \\
Ash & 0.115 & & & \\
VC & 4.6 & & & \\
\hline
\end{tabular}

weight fractions have been calculated considering the corresponding conversion degrees and the yield coefficients of each reaction.

The reaction order of some reactions is quite different from the unity (reaction order extensively used in literature), so all the runs were also correlated with first-order reactions. The results are shown in Table 3. Although the variation coefficient only increases from $4.0 \%$ to $4.6 \%$, the differences between the experimental results and the calculated ones are significant, mainly in the DTA graphs. Comparing Tables 2 and 3, some similarities between the parameters obtained can be observed, but due to the shape of the curves shown in the previous figures and the fact of that dynamic and isothermal runs were correlated with the same set of parameters, the values shown in Table 2 can be the adequate ones to be used as kinetic parameters but must be considered as correlation parameters.

Concerning the kinetic parameters of the pyrolysis process, the following aspects can be considered. There is an initial small fraction (volatile fraction around 0.07-0.085), from which volatiles evolve around $300-370 \mathrm{~K}$, with a small apparent activation energy (64-67 kJ/mol), corresponding mainly to the humidity of the sample. This small value of activation energy is similar to that of $58.2 \mathrm{~kJ} / \mathrm{mol}$ proposed by Leoni et al. [11] in the dehydration kinetics of Pinus pinaster samples.

After the evolution of volatiles corresponding to the first fraction, a second fraction decomposes at 470-600 K, with an apparent activation energy of $117-122 \mathrm{~kJ} / \mathrm{mol}$, and probably corresponds mainly to the hemicellulose. This value is close to the value $110 \mathrm{~kJ} / \mathrm{mol}$ proposed for the hemicellulose in literature [12].

The following fraction decomposed in the range $550-700 \mathrm{~K}$ with an apparent activation energy value around $144-240 \mathrm{~kJ} /$ mol. It has been suggested that cellulose decomposes in the range $300-400{ }^{\circ} \mathrm{C}$ with an apparent activation energy around 150 $250 \mathrm{~kJ} / \mathrm{mol}[9,13-15]$, so this third fraction must correspond to cellulose. Two reviews of the kinetics of the thermal decomposition of cellulose have been published recently by Antal and Varhegyi [14] and Milosavljevic and Suuberg [15]. In accordance with Antal and Varhegyi [14], under conditions which minimize vapour-solid interactions and heat transfer intrusions, the TG and DTG curves associated with the pyrolysis of a wide variety of pure cellulose samples can be well fitted by an irreversible, single step, first order rate equation with a high activation energy (ca.
$238 \mathrm{~kJ} / \mathrm{mol}$ ). On the other hand, Milosavljevic and Suuberg [15] considered that depending upon the heating rate, the pyrolysis of cellulose at a low temperature regime is characterized by an activation energy around $218 \mathrm{~kJ} / \mathrm{mol}$ and a reaction order that seems to go from zero, very early in the process, to one throughout most of the process.

There is a fourth fraction that decomposes above $800 \mathrm{~K}$ with an apparent activation energy around $64-80 \mathrm{~kJ} / \mathrm{mol}$ that corresponds mainly to lignin. Normally, lignin decomposes in a wide interval of temperatures, so this fraction, must be referred to the fraction that decomposes at high temperature, whereas the fraction that decomposes at low temperature probably is included in the fractions 2 and 3. It must be emphasized that the kinetic models proposed reproduce the experimental data in an extensive interval of operating conditions, but their fractions can only be partially associated with the chemical composition. In literature, the values of activation energy proposed vary significantly among the different authors. Grønly et al. [16] studied the devolatilization kinetics of wood, and deduced the following values of activation energies for first order reactions: $100 \mathrm{~kJ} / \mathrm{mol}$ for hemicellulose, $236 \mathrm{~kJ} / \mathrm{mol}$ for cellulose and $46 \mathrm{~kJ} / \mathrm{mol}$ for lignin.

High values of reaction orders can be explained as a decrease in specific surface of the non-reacted samples, so the correlations obtained with reaction orders greater than unity are also admissible [17].

The apparent activation energy obtained for the combustion of the char formed (160-185 kJ/mol) is similar to that proposed in literature. Haji-Sulaiman and Aroua [18] proposed values around $135 \mathrm{~kJ} / \mathrm{mol}$ for the oxidation of Malaysian coal chars. From the data presented by Henrich et al. [19], values of apparent activation energy around $140 \mathrm{~kJ} / \mathrm{mol}$ have been proposed for oxidation in pure oxygen of soot, graphite, activated charcoals and chars of municipal waste and electronic scrap. Walker et al. [20] proposed an apparent activation energy around $209-242 \mathrm{~kJ} / \mathrm{mol}$ for the reaction: $\mathrm{C}+1 / 2 \mathrm{O}_{2} \rightarrow \mathrm{CO}$. The oxygen reaction order deduced in this work for the combustion reactions is the unity, similar to that considered in the gasification of carbon [21].

The weight fractions of hemicellulose, cellulose and lignin obtained from the analysis and from the correlation of the data are presented in Table 4 . In this table, it has been assumed that $V_{2}$ corresponds to hemicellulose (Tables 3 and 4 ), $V_{3 c p}$ or $V_{3}+V_{3 c}$ corresponds to cellulose and $V_{4 \mathrm{cp}}$ corresponds to lignin. There is an acceptable concordance for the parameters of cellulose and lignin. Müller-Hagedorn and Bockhorn [4] analysed the kinetic parameters of thermal decomposition of hemicellulose, cellulose and lignin in the biomass, observing an acceptable concordance in some cases, but not in all the samples. Therefore the real kinetic model, valid in an interval of operating conditions, must be obtained from the correlation of the experimental data. In this paper, it must be emphasized that all the data of pyrolysis, combustion in two atmospheres, dynamic and dynamic + isothermal runs have been correlated satisfactorily with the pyrolysis and combustion models, and the kinetic parameters obtained must be considered as correlation parameters, but useful in an extensive interval of operating conditions.

Table 4

Comparison of contents

\begin{tabular}{lcl}
\hline & $\begin{array}{l}\text { Content in the } \\
\text { tomato plant (\%) }\end{array}$ & $\begin{array}{l}\text { Percentage of volatile } \\
\text { mass on dry basis (\%) }\end{array}$ \\
\hline Ethanol extract & 5.1 & \\
Hemicellulose & 28.8 & $15.2-20.0^{\mathrm{a}}$ \\
Cellulose & 39.1 & $42.9-42.1^{\mathrm{a}}$ \\
Lignin & 12.1 & $16.0-13.4^{\mathrm{a}}$ \\
\hline
\end{tabular}

\footnotetext{
a Obtained with reaction order 1 .
} 


\section{Tomato plant. He}

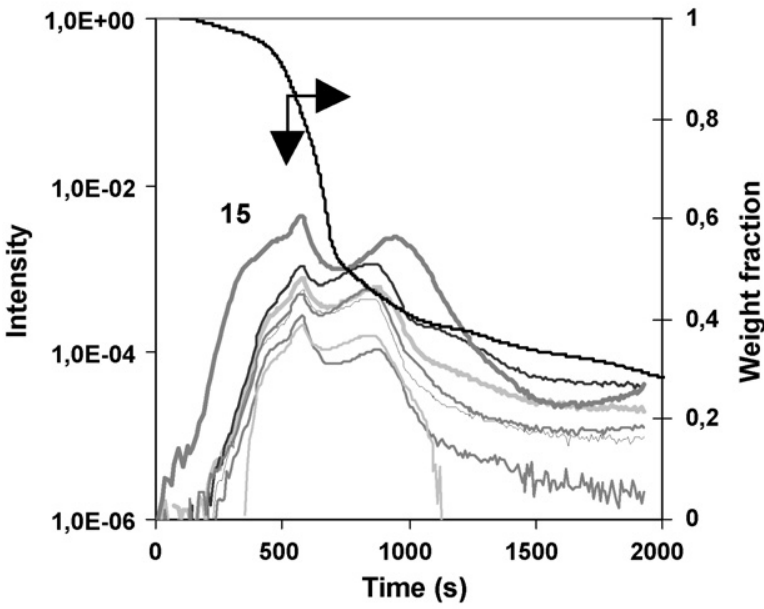

Fig. 13. Variation of ions 15 (methane), 25 (acetylene), 26 (ethane, ethylene, acetylene), 27 (ethylene, ethane, propane, propene, butane, butane), 39 and 41 (propane, propene, butane, butane), 40 (propene) in a pyrolysis TG/MS run (He atmosphere)

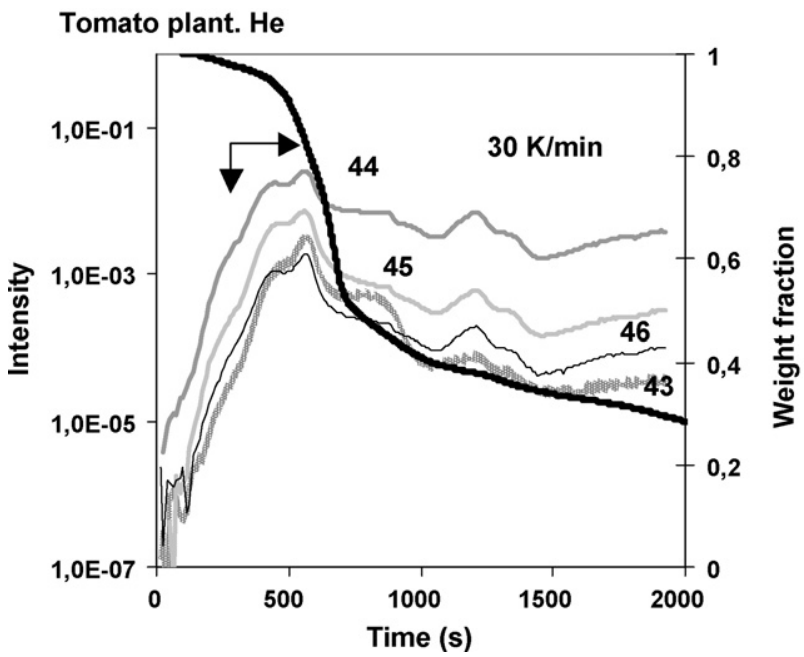

Fig. 14. Variation of ions 44 (carbon dioxide), 43 (acetic acid, acetaldehyde, acetone, 3-methyl-1-butanol), 45 (acetic acid, formic acid, propionic acid, 2-propanol, hidroxyacetone), 46 (formic acid) in a pyrolysis TG/MS run (He atmosphere).

\section{Analysis of the data obtained from the TG-MS data}

Figs. 3 and 7 show the variation of the intensity ions corresponding to water $(m / z 18)$, carbon monoxide $(m / z 28)$, carbon dioxide $(\mathrm{m} / \mathrm{z} 44)$ and methane $\left[\mathrm{CH}_{3}+\right](\mathrm{m} / \mathrm{z} 15)$ in a helium atmosphere and in a 4:1 $\mathrm{He}: \mathrm{O}_{2}$ atmosphere, respectively.

Fig. 13 shows the variation of the weight fraction of the ions $(\mathrm{m} /$ z) $15,25,26,27,39,40,41$ corresponding to methane, ethylene, acetylene, propylene, ethane, propane, butane, etc. The curve corresponding to the ion 15 is the highest one, and those corresponding to the other ions have a similar variation. A similar behaviour can be observed in the combustion run, taking into account that the process begins at low temperature and there is not a strong oxidation of the gases.

Fig. 14 shows the evolution of the ion 44 (carbon dioxide), 43 (acetic acid, acetaldehyde, acetone, 3-methyl-1-butanol), 45 (acetic acid, formic acid, propionic acid, 2-propanol, hidroxyacetone) and 46 (formic acid) in a pyrolysis run. It can be observed that the decarboxylation process takes place in a way parallel to the evolution of oxygenated compounds. Similar conclusions can be deduced from the combustion run.

It can be observed that the evolution of the ions takes place along the runs. All these curves show a decomposition band, overlapping of different fractions and illustrate the difficulty in simulating the real process of decomposition.

\section{Conclusions}

Two kinetic models for the pyrolysis and combustion of tomato plant have been obtained, which correlate dynamic and isothermal runs with the same set of parameters. It has been tested that an acceptable correlation can be obtained for dynamic runs at different heating rates and isothermal runs at distinct operating temperatures.

An acceptable correspondence between the weight of volatiles and the composition of the waste has also been observed.

\section{Acknowledgment}

Support for this work was provided by Spanish MEC, research project CTQ2005-05262.

\section{References}

[1] J.F. Gónzalez, C.M. González-García, A. Ramiro, J. González, E. Sabio, J. Gañan, M.A. Rodríguez, Biomass Bioenergy 27 (2004) 145

[2] J.F. Gónzalez, C.M. González-García, A. Ramiro, J. Gañan, A. Ayuso, J. Turegano, Fue Process Technol. 8 (2006) 717.

[3] V. Mangut, E. Sabio, J. Gañan, J.F. González, A. Ramiro, C.M. González, S. Román, A Al-kassir, Fuel Process Technol. 87 (2006) 109.

[4] M. Müller-Hagedorn, H. Bockhorn, J. Anal. Appl. Pyrolysis 79 (2007).

[5] R.R. Rowell, R.A. Young, J. Rowell (Eds.), Paper and Composites from Agro-Based Resources. Chapter 3. Analytical Procedures, CRC Press, 1996.

[6] Technical Association for the Pulp and Paper Industries (TAPPI), Preparation of extractive free-wood. TAPPI Test Method T 12 os-75, TAPPI PRESS, Atlanta, 1978

[7] Technical Association for the Pulp and Paper Industries (TAPPI), Acid-insoluble in wood and pulp. TAPPI Test Method T 222 os-74, TAPPI PRESS, Atlanta, 1978.

[8] Technical Association for the Pulp and Paper Industries (TAPPI), Alpha-, Beta- and Gamma Cellulose in pulp. TAPPI Test Method T 203 os-74, TAPPI PRESS, Atlanta, 1978.

[9] M. Grønli, M.J. Antal, G. Várhegyi, Ind. Eng. Chem. Res. 38 (1999) 2238

[10] I. Martín-Gullón, M.F. Gómez-Rico, A. Fullana, R. Font, J. Anal. Appl. Pyrolysis 6869 (2003) 645

[11] E. Leoni, P. Tomi, B. Khoumeri, N. Blabi, J. Fire Sci. 19 (2001) 379.

[12] R. Font, A. Marcilla, E. Verdú, J. Devesa, J. Anal. Appl. Pyrolysis 21 (1991) 29.

[13] M.J. Antal, H.L. Friedman, F.E. Rogers, Combust. Sci. Technol. 21 (1980) 141.

[14] M.J. Antal, G. Varhegyi, Ind. Eng. Chem. Res. 34 (1995) 703.

[15] I. Milosavljevic, E.M. Suuberg, Ind. Eng. Chem. Res. 34 (1995 1081).

[16] M.G. Grønly, G. Várhegyi, C. Di Blasi, Ind. Eng. Chem. Res. 41 (17) (2002) 4201.

[17] R. Font, A. García, J. Anal. Appl. Pyrolysis 35 (1995) 249.

[18] M.Z. Haji-Sulaiman, M.K. Aroua, J. I. Energy 70 (1997) 52.

[19] E. Henrich, S. Bürkle, Z.I. Meza-Renken, S. Rumpel, J. Anal. Appl. Pyrolysis 9 (1999) 133.

[20] P.L. Walker, F. Rusinko, L.G. Austin, Adv. Catal. 9 (1959) 133.

[21] Z. Du, A.F. Sarofim, J.P. Longwell, J. Lahay, P. Ehrburger, Fundamental Issues in Control of Carbon Gasification, 1992, p. 91 